\section{Studi Perilaku Balok Beton Bertulang Dengan Variasi Letak Bukaan Menggunakan Metode Elemen Hingga}

\section{Eka Purnamasari}

Dosen Jurusan Teknik Sipil, Fakultas Teknik Universitas Islam Kalimantan Muhammad Arsyad Al-Banjari Banjarmasin.

eka.ftsuniska@gmail.com
Jaringan utilitas pada konstruksi gedung bertingkat yaitu seperti saluran kabel listrik, perpipaan, kabel telepon, pendingin ruangan dan lain-lain, biasanya ditempatkan pada ruang dibagian atas plafon atau dipasang menempel pada balok. Dengan meletakkan utilitas pada balok dapat meminimalisasi tinggi atau space dari ruang, juga akan mereduksi volume beton yang digunakan serta lebih rapi. Maka akan memungkinkan untuk mendesain bukaan pada balok beton bertulang, dimana selain berfungsi sebagai struktur yang menahan dan menyalurkan bebanbeban yang bekerja di atasnya, tapi juga berfungsi sebagai pendukung utilitas. Pelaksanaan penelitian ini di program Finite Elemen Method dikondisikan sama dengan keadaan di lapangan. Dalam penelitian dibuat 3 (tiga) variasi letak bukaan, sehingga total model menjadi 3 buah. Dimensi lubang yang digunakan yaitu luas lubang $270 \mathrm{~cm}^{2}$ atau ukuran perseginya yaitu 16,43 x 16,43 $\mathrm{cm}^{2}$. Variasi letak bukaan pada balok mempengaruhi kemampuan balok menahan beban. Semakin banyak jumlah lubang semakin kecil kemampuan balok menahan beban dan letak bukaan pada daerah lapangan lebih baik dalam menahan beban daripada didaerah tumpuan. Hal ini terlihat dari perilaku deformasi yang terjadi sebelum keruntuhan terjadi. Retak yang terjadi pada semua model kebanyakan adalah retak vertikal, hal ini mengindikasikan bahwa sangat diperlukan penambahan tulangan tarik untuk mencegah lebih awal keruntuhan lentur beton yang bersifat getas.

Kata kunci : balok, beton, bukaan, finite elemen method

Dlpresentasikan: 30 Agustus 2019

Direvisi: 14 September 2019

Diterima: 2 Oktober 2019

Dipublikasikan online: 5 Oktober 2019

\section{Pendahuluan}

Pada konstruksi gedung bertingkat biasanya membutuhkan jaringan utilitas yaitu seperti saluran kabel listrik, perpipaan, kabel telepon, pendingin ruangan dan lain-lain. Pada umumnya jaringan ini ditempatkan pada ruang dibagian atas plafon atau dipasang menempel pada balok. Penempatan untilitas ini dapat mengurangi tinggi atau luas ruangan pada bangunan serta terlihat tidak rapi jika dilihat dari segi estetika, sehingga diperlukan alternatif desain yang diantaranya dengan memanfaatkan ruang-ruang pada balok struktur. Maka akan memungkinkan untuk mendesain lubang pada balok beton bertulang, dimana selain berfungsi sebagai struktur yang menahan dan menyalurkan beban-beban yang bekerja di atasnya, tapi juga berfungsi sebagai pendukung utilitas. Selain itu, pada balok dapat meminimalisasi tinggi atau space dari ruang, juga akan mereduksi volume beton yang digunakan serta lebih rapi.

Studi secara eksperimental maupun analitis tentang balok beton bertulang dengan satu bukaan sudah banyak dilakukan. Bahkan studi tersebut sudah menghasilkan prosedur desain untuk balok beton bertulang dengan satu bukaan (Mansur dkk., 1985; Tan
\& Mansur, 1996; Mansur, 1999). Balok dengan bukaan dapat direncanakan dengan baik sesuai kebutuhan sebelum struktur bangunan didirikan di lapangan. Untuk mencegah kerusakan bukaan akibat beban yang bekerja pada balok. Pada balok beton bertulang berlubang akan terjadi pengurangan kekuatan struktur balok atau terjadi perlemahan pada balok akibat pengurangan dimensi penampang. Selain itu, pembuatan lubang pada balok dapat mengurangi kekakuan dari balok tersebut. Agar stabilitasnya terjamin, diperlukan analisis yang tepat untuk mengetahui pengaruh lubang pada penulangan balok beton bertulang.

Dalam penelitian dibuat tiga variasi letak bukaan dimana satu bukaan diletakkan di daerah lapangan, dua bukaan di daerah tumpuan dan tiga bukaan diletakkan pada daerah lapangan dan tumpuan sehingga total model menjadi 3 buah. Dimensi lubang yang digunakan yaitu luas lubang $270 \mathrm{~cm}^{2}$ atau ukuran perseginya yaitu $16,43 \times 16,43 \mathrm{~cm}^{2}$. Masing-masing model akan diberikan beban hingga terjadi keruntuhan, sehingga dapat dibandingkan kemampuan masing-masing model dalam menahan beban. Tujuan dari penelitian ini adalah untuk mengetahui perilaku balok beton mutu normal dengan

Cara mensitasi artikel ini:

Purnamasari, E (2019) Studi Perilaku Balok Beton Bertulang Dengan Variasi Letak Bukaan Menggunakan Metode Elemen Hingga. [Edisi Khusus]. Buletin Profesi Insinyur 2(3): 111-114 
variasi letak bukaan menggunakan metode elemen hingga.

\section{Metode}

Penelitian ini dilaksanakan dengan metode analisis yaitu dengan perhitungan dan program software Finite Elemen Method (FEM). Tiga model dibuat dalam program metode elemen hingga, dengan input data material beton dan baja. Kemudian model diberikan beban maksimum sampai mengalami keruntuhan. Hasil running FEM dikumpulkan dan disimpulkan agar dapat melihat perilaku yang terjadi pada setiap model balok beton.

\section{Hasil dan Analisa}

\section{Perilaku Lendutan dan Tegangan pada Balok Beton dengan Variasi Letak Bukaan}

Terlihat pada Gambar 1, pada balok dengan variasi letak bukaan. Besarnya lendutan pada balok dengan satu buah bukaan didaerah lapangan yaitu 4,6657 $\mathrm{mm}$, model balok dengan dua bukaan didaerah tumpuan yaitu 4,6673 $\mathrm{mm}$ dan model balok dengan tiga bukaan didaerah lapangan dan tumpuan yaitu 4,6800 $\mathrm{mm}$. Dari hasil tersebut dapat disimpulkan nilai lendutan akan semakin besar apabila jumlah lubang pada balok semakin banyak. Hilangnya sejumlah luasan penampang efektif balok mempengaruhi kekakuan balok sehingga memperbesar nilai lendutan yang terjadi.

Pada model dengan variasi letak bukaan, perbandingan tegangan dapat dilihat pada Gambar 2. Pada model yang memiliki satu buah bukaan didaerah lapangan memiliki tegangan paling besar yaitu 14,4633 Mpa, model yang memiliki dua buah bukaan di daerah tumpuan memiliki tegangan sebesar 14,0901 Mpa dan model yang memiliki tiga buah bukaan didaerah lapangan dan tumpuan memiliki tegangan sebesar 14,1300 Mpa. Penempatan lubang pada daerah momen lapangan dan tumpuan ternyata mempengaruhi tegangan yang terjadi pada balok, lubang yang ditempatkan ditumpuan memiliki rasio tegangan 0,9742 lebih kecil daripada balok dengan lubang didaerah lapangan.

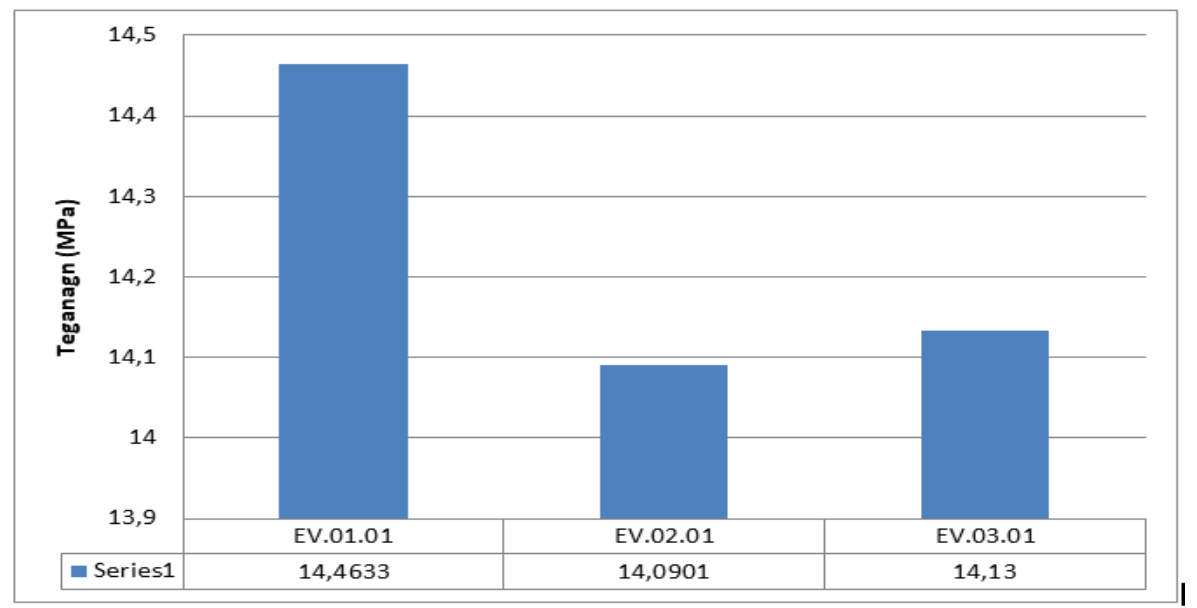

Gambar 1. Perbandingan Lendutan pada Balok Berlubang dengan Variasi Bukaan

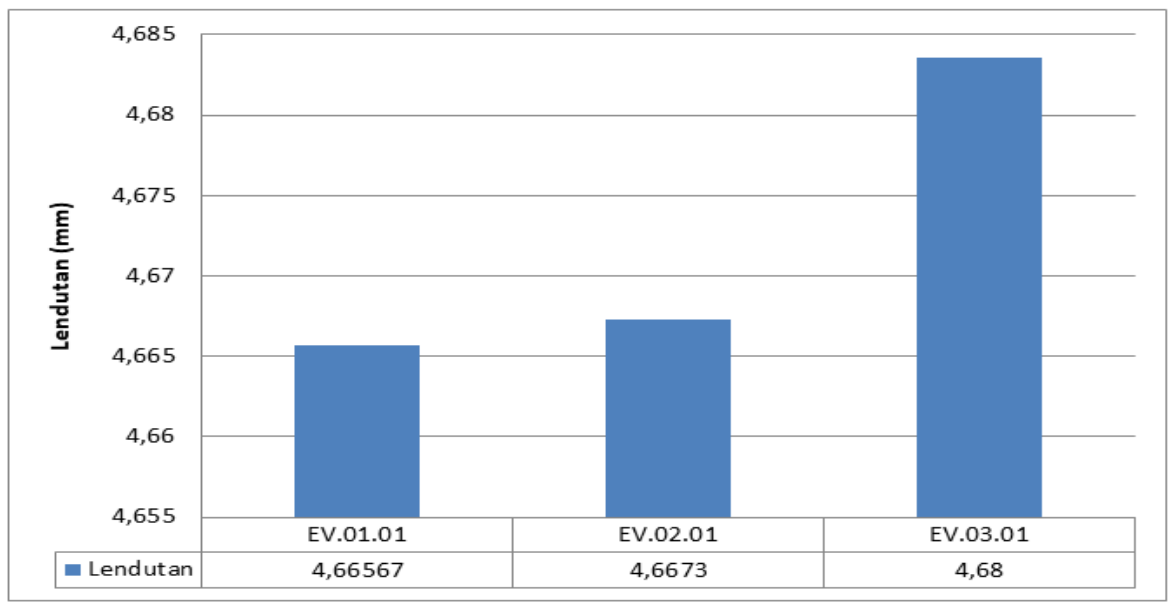

Gambar 2. Perbandingan Tegangan pada Balok Berlubang dengan Variasi Bukaan 
Kurva Tegangan dan Lendutan yang terjadi pada semua model balok dapat terlihat pada Gambar 3. Pada model dengan satu buah bukaan didaerah lapangan memiliki hasil yang paling baik, bahkan pada model yang memiliki tiga buah bukaan yang ditempatkan di daerah lapangan dan tumpuan memiliki kekuatan mendekati dengan model dengan satu bukaan didaerah lapangan. Sedangkan model yang memiliki dua buah bukaan yang ditempatkan pada daerah tumpuan ternyata memiliki hasil yang paling rendah. memiliki tegangan lebih besar dari model yang dilubangi didaerah tumpuan.

\section{Perilaku Retak pada Balok Beton dengan Variasi Letak Bukaan}

Pada hasil FINITE ELEMEN METHOD, dapat dilihat sebaran tegangan, deformasi dan retak yang terjadi pada model. Tegangan dan deformasi yang terjadi pada balok dengan satu bukaan pada daerah lapangan dapat dilihat pada Gambar 4(a). Terlihat bahwa tegangan maksimum terjadi pada daerah pembebanan, pada bukaan, dan menyebar hingga ke daerah tumpuan. Pada Gambar 4(b) dapat dilihat pola retak yang terjadi, retak pertama terjadi pada daerah tumpuan yang selanjutnya terjadi menyebar disepanjang badan balok, terutama pada daerah bukaan.

Tegangan dan deformasi yang terjadi pada balok dengan dua bukaan pada daerah tumpuan dapat dilihat pada Gambar 4 (c), terlihat bahwa tegangan maksimum berada pada daerah pembebanan dan pada daerah tumpuan. Pada Gambar 4(d) dapat dilihat pola retak yang terjadi, retak pertama terjadi pada daerah tumpuan yang selanjutnya terjadi didaerah lapangan.

Tegangan dan deformasi yang terjadi pada balok dengan tiga bukaan pada daerah lapangan dan tumpuan dapat dilihat pada Gambar 4(e), terlihat bahwa tegangan maksimum berada pada daerah pembebanan menyebar hingga pada bukaan didaerah lapangan dan daerah tumpuan. Pada Gambar 4(f) dapat dilihat pola retak yang terjadi, retak pertama terjadi pada daerah tumpuan yang selanjutnya terjadi didaerah lapangan, terutama pada bukaan yang berada didaerah lapangan.

\section{Kesimpulan}

Jumlah bukaan pada balok beton bertulang mempengaruhi kemampuan balok menahan beban. Semakin sedikit jumlah lubang semakin optimal balok menahan beban. Balok dengan bukaan didaerah tumpuan memiliki rasio tegangan 0,9742 lebih kecil daripada bukaan didaerah lapangan. Penempatan bukaan pada daerah lapangan lebih baik dalam menahan beban namun akan terjadi retak disekitar bukaan. Berbeda dengan bukaan yang ditempatkan di daerah tumpuan, walaupun kekuatan balok menjadi kurang optimal namun tidak terjadi retak pada daerah bukaan. Retak yang dihasilkan kebanyakan adalah retak vertikal, ini menunjukkan bahwa sangat diperlukan penambahan tulangan tarik untuk mencegah lebih awal keruntuhan lentur beton yang bersifat getas.

\section{Ucapan Terimakasih}

Terima kasih kepada Universitas Islam Kalimantan Muhammad Arsyad Al-Banjari Banjarmasin atas bantuan biaya dalam penelitian ini.

\section{Referensi}

Mansur, M.A, (1999) Design of reinforced concrete beams with small opening under combined loading, ACl Structural Journal, Vol. 96, No. 5, SeptemberOctober, 675682.

Mansur, M.A., Tan, K.H., and Lee, S.L., (1984) Collapse loads of $R / C$ beam with large opening, Journal of the Structural Division, ASCE, Vol. 110, No. 11, November, 2602-2618.

Mansur, M.A., Tan, K.H., and Lee, S.L., (1985) Design methods for reinforced concrete beams with large opening, ACl Journal, Vol. 82, July-August, 517-524.

Setiawan, A. (2016). Perancangan Struktur Beton Bertulang berdasarkan SNI 2847 : 2013. Jakarta: Erlangga

Gambar 3. Kurva Tegangan dan Lendutan Beton pada Balok Berlubang dengan Variasi Bukaan

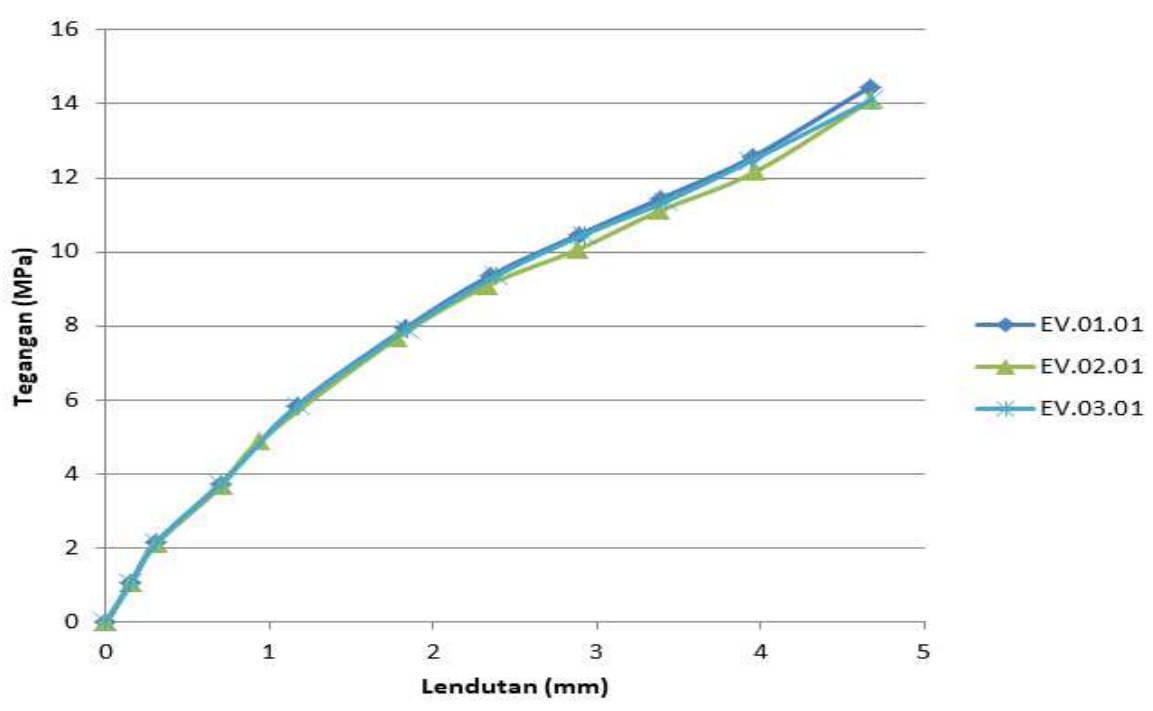



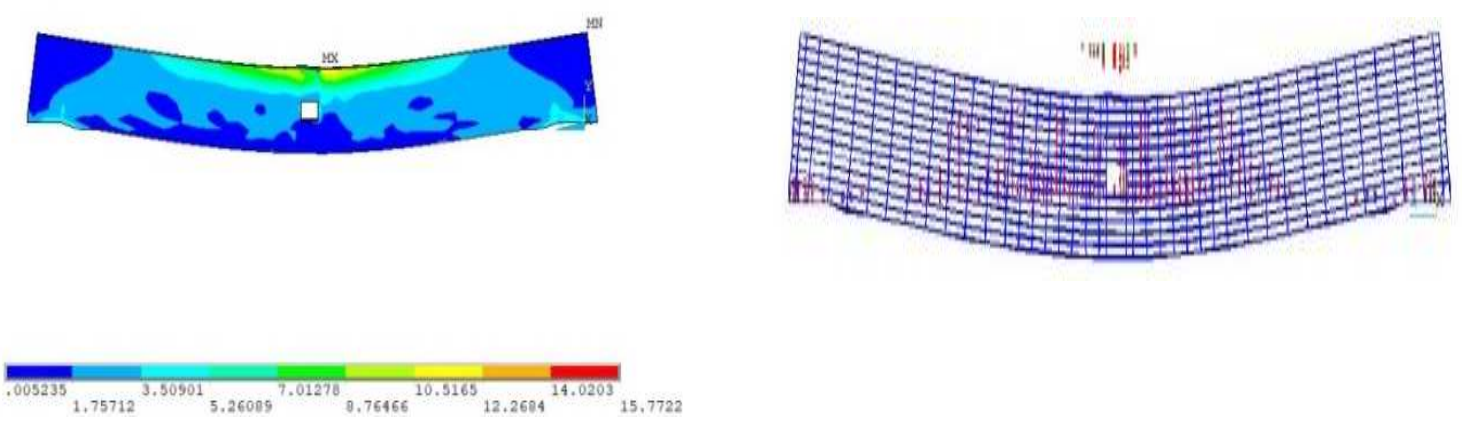

(a) Tegangan Pada Model Satu Bukaan

(b) Pola Retak Pada Model Satu Bukaan
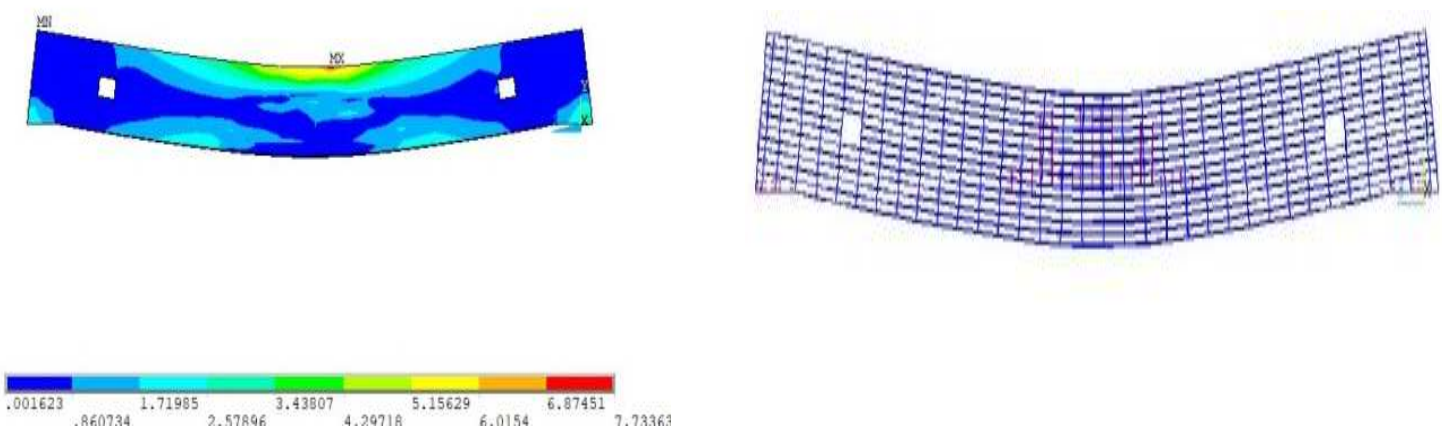

(c) Tegangan Pada Model Dua Bukaan

(d) Pola Retak pada Model Dua Bukaan
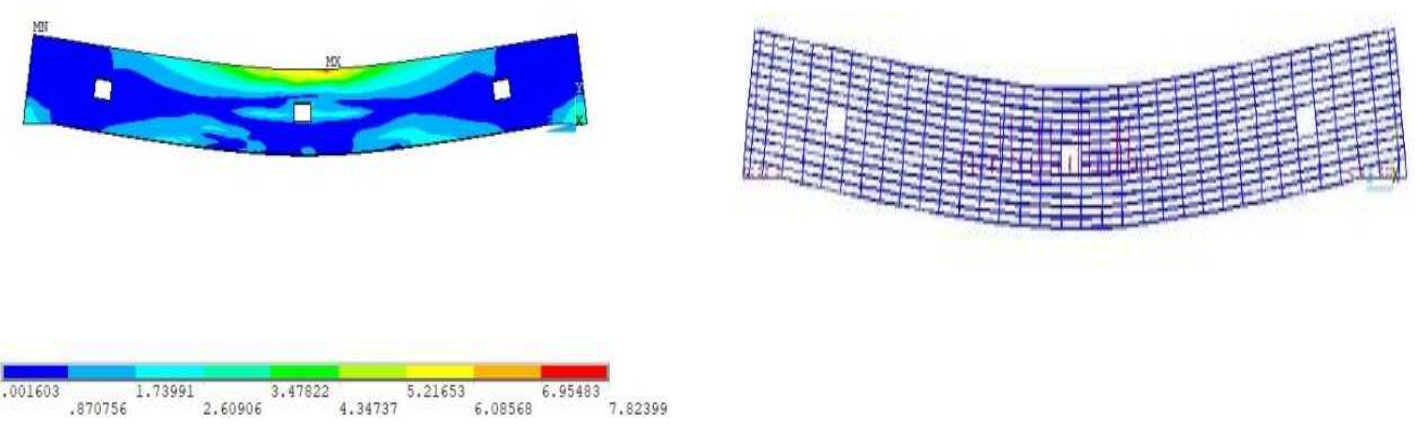

(e) Tegangan Pada Model Tiga Bukaan

(f) Pola Retak Pada Model Tiga Bukaan

Gambar 4. Tegangan dan Pola Retak pada Model 